\title{
El derecho a la objeción de conciencia
}

\section{The right to conscientious objection}

\author{
David Ulises Guzmán Palma ${ }^{1}$ \\ FES-ACATLÁN UNAM (México)
}

Recibido: 16 de octubre de 2018

Aceptado: 08 de abril de 2019

Publicado: 19 de junio de 2019

\section{Resumen}

El presente estudio analiza la objeción de conciencia como un derecho humano con el apoyo metodológico de la fenomenología y el derecho constitucional, con el objetivo de aportar una vía concreta para delimitar y ejercer este derecho. Por tal motivo, se propone crear un derecho subjetivo que permita al ciudadano ejercer su derecho a la objeción de conciencia, basado en el uso de la razón, en la explicación de los elementos subjetivos, de la objetividad existente en el mundo

\footnotetext{
${ }^{1}$ Email: $\underline{\text { lic.david.juridicogm@outlook.com }}$
}



Revista del Centro de Investigación. Universidad La Salle por Dirección de Posgrado e Investigación. Universidad La Salle Ciudad de México se distribuye bajo una Licencia Creative Commons Atribución-NoComercial-Compartirlgual 
circundante y el acto objetivante que motiva la decisión, creando así un camino procesal para hacer realidad de forma universal el derecho a la objeción de conciencia.

Palabras clave: Conciencia; Derechos Humanos; Dignidad Humana; Objetividad; Subjetividad 


\section{Abstract}

The present study analyzes conscientious objection as a human right with the methodological support of phenomenology and constitutional law, with the aim of providing a concrete way to delimit and exercise this right. For this reason, it is proposed to create a subjective right that allows citizens to exercise their human right to conscientious objection, based on the use of reason, on the explanation of the subjective elements and the significant act that motivates the decision, creating thus a procedural path to make universally the human right to conscientious objection.

Keywords: Consciousness; Human Rights; Human Dignity; Objectivity; Subjectivity 


\section{Introducción}

Si se entiende a la conciencia como el resultado de una objetivación de lo subjetivo y lo objetivo, es entonces un proceso de discernimiento que ofrece las bases o razones para enjuiciar, objetar, aplicar o tomar decisiones ante un fenómeno concreto y en su momento para construir argumentos que justifiquen una decisión a conciencia.

El presente ensayo se concentra en explicar tres elementos para la edificación de unas bases mínimas que debe contener una ley en materia de objeción de conciencia:

a) La estructura de la conciencia como proceso objetivante;

b) El derecho a la libertad del pensamiento como núcleo de la objeción de conciencia;

c) El reconocimiento de un derecho subjetivo generalizado que tenga por pretensión la inaplicación de una ley, lo que implica la vigencia en el derecho procesal de la figura de objeción de conciencia.

Rubros que observan el fenómeno como un hecho concreto en una realidad determinada, dando justo valor a la visión del derecho como un sistema útil para la convivencia humana y a la filosofía fenomenológica como método que explica qué es la conciencia y cuál es su estructura.

\section{1. ¿Qué es la objeción conciencia? y ¿cuál es su estructura?}

En el presente capítulo se discernirán las nociones de conciencia y sus elementos circundantes como la objetividad y la subjetividad. Así mismo, se profundizará en su esencia y en sus bases que son la libertad y dignidad-, con el apoyo metodológico de la fenomenología.

Una reflexión especial tendrá la figura de objeción de conciencia al describir sus acepciones y estructura básica.

\section{1 ¿Qué es la conciencia?}

Los diversos sentidos de la palabra conciencia muestran los fines en la que es aplicable:

1. Capacidad del ser humano para darse cuenta de sí mismo y de lo que lo rodea.

2. Facultad que tiene el ser humano de conocer y juzgar sus propios actos y los de los demás.

3. Examen de conciencia acto de reflexión y juicio sobre las acciones propias. 
4. Sentimiento de una persona, después de haber reflexionado y juzgado sus actos. 5. Cargo de conciencia o remordimiento de conciencia. Sentimiento de culpabilidad por haber actuado en forma que uno considera incorrecta. (Diccionario del español de México, COLMEX, 2019).

Es importante precisar que, en el presente estudio, la conciencia se describe fenomenológicamente, es decir como capacidad humana de sí mismo en su mundo circundante, en un momento y lugar determinado, en un ser ahí, en términos del pensamiento del Dasein (Gambra, 1996) ${ }^{2}$, lo que permite que el ser tenga capacidad de decisión, a partir de los saberes que existen en su conciencia. Este ser en el mundo (Dasein), ve la praxis de la conciencia como facultad, como juicio, como acto de reflexión propia y como un compromiso moral hacia los demás miembros de la sociedad, lo que implica que la conciencia engloba a la subjetividad, a la moral colectividad, a los saberes del mundo que nos rodea, al discernimiento y es a su vez base para la toma de decisiones importantes. Esto se explica al describir diversas formas de aplicación de la conciencia, observemos:

Tabla 1. Clasificación de la conciencia

\begin{tabular}{lccc}
\hline Conciencia subjetiva & $\begin{array}{c}\text { Conciencia moral } \\
\text { colectiva }\end{array}$ & $\begin{array}{c}\text { La conciencia ante } \\
\text { un fenómeno } \\
\text { específico }\end{array}$ & $\begin{array}{c}\text { La conciencia como } \\
\text { algo que existe en el } \\
\text { mundo e interactúa } \\
\text { en el mundo } \\
(\text { dasein) })\end{array}$ \\
\hline & & $\begin{array}{l}\text { Capacidad del ser } \\
\text { humano para darse } \\
\text { cuenta de sí mismo y } \\
\text { de lo que lo rodea }\end{array}$ \\
& $\begin{array}{l}\text { Facultad que tiene el } \\
\text { ser humano de } \\
\text { conocer y juzgar sus } \\
\text { propios actos y los de } \\
\text { los demás }\end{array}$
\end{tabular}

\footnotetext{
${ }^{2}$ Lo que Heidegger llama el Dasein es una palabra alemana difícilmente traducible, se suele transcribir en todos los idiomas. Significa "ser-ahí" y, en definitiva, se refiere al hombre como arrojado a la existencia; ser que existe en el mundo y actúa sobre las cosas, que tienen, ante todo, el sentido de instrumentos.
} 
Examen de conciencia.

Acto de reflexión y juicio sobre las acciones propias

Sentimiento de una persona, después de haber reflexionado $\mathrm{y}$ juzgado sus actos

Cargo de conciencia o remordimiento de conciencia.

Sentimiento de culpabilidad por haber actuado en forma que uno considera incorrecta

$$
\begin{aligned}
& \text { Compromiso moral } \\
& \text { de una persona } \\
& \text { hacia los demás }
\end{aligned}
$$

$\begin{array}{ll} & \begin{array}{l}\text { A conciencia con } \\ \text { responsabilidad y } \\ \text { cuidado } \\ \text { Tomar conciencia, } \\ \text { darse cuenta de algo }\end{array} \\ \text { Crear conciencia } \\ \text { Hacer que los } \\ \text { demás se den } \\ \text { cuenta de algo y lo } \\ \text { tomen en serio }\end{array}$

Fuente: Elaboración propia con datos del Diccionario de español de México, (COLMEX, 2019).

De tal forma que la conciencia no solo se queda en la psique, sino que al tomar una decisión se exterioriza en conductas específicas y sus efectos trascienden al mundo circundante.

Sin embargo, es un error concentrarse en los efectos de los actos externos y restarle importancia a la estructura de la conciencia, ya que en el proceso de integración de la conciencia 
están las causas que llevan a la toma de una decisión a conciencia. En consecuencia, comprender el proceso ayuda a clarificar la expresión de los argumentos que justifican esta decisión.

Para el filósofo mexicano Sánchez la conciencia es un fenómeno que tiene la siguiente estructura:

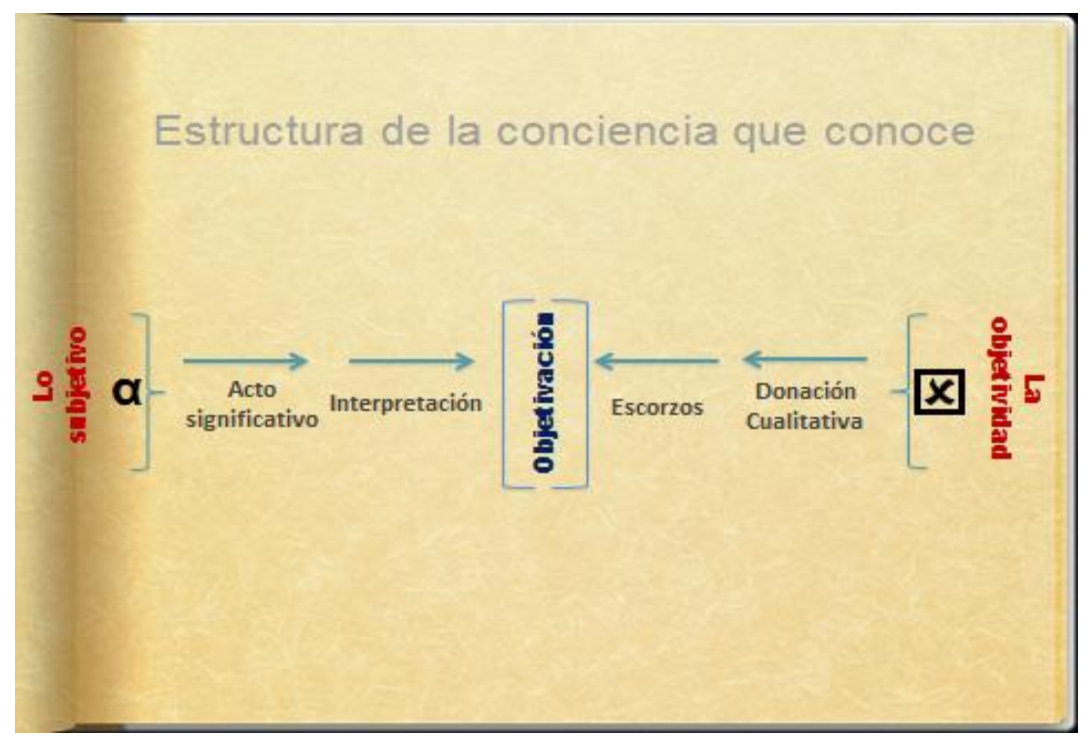

Figura 1: Estructura de la conciencia. Recuperado de Sánchez, R. "Posibilidades prácticas y posibilidades modales como base de actos reales en el curso Introducción a la filosofía de Edmundo Husserl, p. 105.

El cuadro anterior se explica con una "Ontología realista [...], que la conciencia está en el ser y que se rige bajo objetividades o posibilidades que pueden ser obtenidas a partir de objetos y realidades existentes efectivas" (Sánchez, 2016, p. 105.), esto con base en la "motivación de los procesos presignificativos y asociativos en la conciencia de imagen: hostilidad y vida natural" (Sánchez, 2016, p. 4.).

De tal forma que la subjetividad y la objetividad se integran en un saber. De las subjetividades se obtienen significados almacenados como interpretaciones y de las objetividades se obtienen donaciones delimitadas por los escorzos, al final mediante un discernimiento y exteriorización la subjetividad y la objetividad se unen en una objetivación o decisión a conciencia.

El paso de los saberes objetivos por el escorzo es clave para llegar a la objetivación, ya que en él se da la contracción proyectiva que permite al individuo idealizar (si hago esto, entonces sucede lo siguiente), en otras palabras, escorzar (desde esta acepción) implica colocar en el plano visual el objeto y buscar a su vez su continuidad, sin ocultar sus elementos. De manera que, al 
escorzar los elementos cuantitativos de la objetividad, idealmente se puedan sintetizar para complementar o confrontarse con los elementos obtenidos mediante la subjetividad, logrando así una proyección mental para la toma de una decisión.

En otras palabras, la conciencia está conformada por dos elementos:

1) La subjetividad del individuo (conocimientos obtenidos por el proceso del aprendizaje y experimentación de cada persona), y;

2) Parámetros de objetividad que existen en el mundo circundante en el que vive el individuo (el derecho, las teorías de la ciencia, la moral colectiva, la religión entre otras).

De suerte que, ante un caso concreto en el que el individuo debe tomar una decisión trascendente, se realiza un ejercicio de objetivación, el cual se integra por la extracción de datos de un hecho específico, en un tiempo y espacio determinado, situación que interpreta el sujeto a través de un filtro configurado por sus conocimientos (obtenidos a través de la experiencia y su proceso de aprendizaje: conocimientos del ámbito intelectual, moral, espiritual y familiar) y que, a su vez, confronta o sintetiza - en su caso- con una donación cualitativa de los parámetros de objetividad vigentes en su mundo circundante, extrayendo normas, principios, opiniones, teorías, que, previo a un proceso de superación de escorzos, buscan ser aplicados al caso concreto que enfrenta el individuo.

La explicación filosófica anterior, que es toral para puntualizar en su respectivo capitulo, los elementos que debe tener un procedimiento de objeción derivado de una decisión realizada a conciencia.

En resumen, basta describir que los elementos cualitativos de la objetividad son extraídos previa selección, para asociarlos o confrontarlos con los datos producto de la subjetividad, a fin de generar una síntesis estructurada por razones, a la cual se le llama objetivación o toma de decisión a conciencia: proceso intelectual que arroja argumentos para que el individuo decida ante un fenómeno determinado lo que debe o no hacer.

La explicación de la estructura de la conciencia permite comprender que la psique de un individuo concreto construye argumentos bases para tomar una decisión a conciencia.

Este ejercicio de conciencia u objetivación alinea todos los saberes contenidos en el ser, como la experiencia, la moral, la espiritualidad y la racionalidad, generando así un estatus de felicidad que permite afrontar problemáticas concretas de forma sorpréndete, a esto se denomina 
un estatus de conciencia feliz y se basa en una explicación de Kant: "la idea de una inteligencia así, en la que la voluntad, moralmente la más perfecta, gozando de la soberana dicha, es la causa de toda felicidad en el mundo, en tanto que esta felicidad está en estrecha relación con la moralidad (es decir, con aquello que hace digno de ser dichoso), esta idea yo la llamo el ideal del soberano bien" (I. Kant, 2012, p. 447).

Por ello, esa idea del soberano bien generadora de felicidad es producto del acomodo congruente dentro de la conciencia de la experiencia+ moralidad+ espiritualidad+ racionalidad+ elementos del mundo circundante en una decisión objetivada o tomada a conciencia.

De tal forma que una objetivación o toma de decisión a conciencia armoniza la experiencia, la moralidad, la racionalidad y la espiritualidad generando un bienestar al saber que se ha decidido por aquello que su conciencia le ordeno, lo que implícitamente implica la construcción de un idealismo que al exteriorizarse puede chocar con el derecho vigente y caer en el estatus del incumplimiento de un deber legal.

Desde esta óptica, quienes viven las consecuencias de una decisión a conciencia, alcanzan una armonización e incluso alegría. Como ejemplos se recuerdan la actitud de los mártires que formaron las primeras comunidades cristianas que vivían con fortaleza su martirio o la decisión del boxeador Cassius Clay que prefiero la cárcel y la pérdida de su título mundial a asistir a la guerra contra Vietnam, entre otras.

Esto explica, pero no justifica en un sistema jurídico, el por qué el hombre tiene opción de cumplir o incumplir las leyes ante una reflexión a conciencia, asumiendo los efectos que conlleva el incumplimiento voluntario de un deber jurídico, descubriendo, así, un elemento clave en el tema, que es la libertad de pensamiento, ya que el hombre no pierde su libertad interna para realizar procesos psíquicos a pesar de estar viviendo en un régimen específico de Estado o de derecho. ${ }^{3}$

Esto sin olvidar que una decisión a conciencia por su proceso de objetivación, escala niveles de profundidad mayores a la materialidad de los entes, no se queda solo en la reflexión de las consecuencias corporales por incumplir una ley, sino que profundiza a un nivel de racionalidad y espiritualidad de tipo filosófico o teológico que tienen un fin diferente a lo material, así que es esto, lo que hace diferente la decisión a conciencia de cualquier otra decisión que solo intenta incumplir

\footnotetext{
${ }^{3}$ Esto en concordancia con la característica externa de toda norma jurídica, por tanto, el hombre no deja de pensar, independientemente de cuál sea el derecho vigente que le aplique.
} 
con una norma o justificar el no realizar una obligación. Es decir, en el nivel de profundidad de la justificación se detecta si estamos o no ante un caso de decisión a conciencia. Por tanto, el parámetro de una decisión a conciencia trasciende del ente corpóreo para residir en el ser y por ello se liga con la dignidad de cada ser humano ya que amabas surgen del ser y son parte de él.

Es importante precisar que "la especulación de la razón en el uso trascendental comprende tres objetos: la libertad de la voluntad, la inmortalidad del alma y la existencia de Dios" (Kant, 2012, p. 441). Por lo que, una decisión a conciencia u objetivación tiene por cimientos la libertad, la dignidad del ser humano y su espiritualidad, por ello en muchas ocasiones la persona prioriza el rendir cuentas ante dios antes de obedecer a un sistema jurídico construido por humanos, este es el caso de la negación a participar en un aborto por parte de los creyentes cristianos o el caso de los testigos de Jehová cuando se niegan a recibir transfusiones de sangre .

También, sería un grave error olvidar que la conciencia, desde su plano metafísico, es también razón para tomar decisiones, si bien este punto ya está contemplado como un conocimiento propio de la subjetividad, es indispensable precisar su importancia rumbo al análisis de la conciencia como derecho de la libertad de religión que se desarrolla en el próximo capítulo.

En ese sentido, se comprende que la conciencia parte del ser y tiene fundamento en el ser y su existencia no requiere una comprobación científica, porque no existe método para ello y, por tanto, se acepta su existencia por considerarse parte del ser, al igual que la dignidad humana; antes bien, sólo se externa con razones de índole moral, espiritual, ética, política o religiosa, esto porque el fundamento de la conciencia es el ser mismo. En este sentido, la razón tiene fuerza por emanar de un ser que tiene dignidad, por el solo hecho de ser humano. Lo cual complica la comprobación de un hecho en el mundo del derecho, ya que, al no ser evaluada la razón por métodos científicos, solo queda la congruencia como cimiento exteriorizado entre la conciencia y la decisión tomada por un individuo en un caso concreto.

En consecuencia, si el ser pensante e individual es el fundamento de la conciencia, el núcleo de la conciencia es el ser de la misma persona y, por tanto, tiene como bien jurídico tutelado el mismo que el de la persona: la dignidad humana.

Al ser la conciencia un acto de objetivación libre del ser, donde combina el discernimiento de elementos objetivos del mundo circundante con interpretaciones producto de subjetividades, se 
integran saberes útiles para la toma de decisiones ante un caso concreto que tiene por base la libertad del pensamiento y la dignidad del ser humano.

Por surgir del ser, esta decisión a conciencia u objetivada no tiene verificación científica, pero si debe contener elementos de coherencia y congruencia entre los saberes y los hábitos del individuo, esto sin perder de vista que una efectiva decisión a conciencia u objetivada se caracteriza por un estado de armonía e incluso alegría por la decisión tomada y prioriza la aplicación de la decisión a conciencia a pesar de los efectos que ella genere en el sistema jurídico vigente.

\section{2. ¿Qué es la objeción?}

La palabra objeción deriva del latín ob-iactare y el significado genérico de tal expresión puede ser entendido como "la oposición y protesta de la conciencia contra una determinada institución o ley" (Agulles Simó, Pau, 2006).

Una objeción busca impedir, controvertir, protestar o argumentar contra algo que parece ya decidido o ya expresado.

Por ello, la objeción es en sí misma un medio y no un fin, es una figura evidentemente procesal que llevará a debate algo que se ordena ejecutar. Por tanto, la objeción, al asociarse con la conciencia, se nutre de razones generadas por un proceso de objetivación para decidir ante un caso concreto sobre un hacer o no hacer.

El objetar es un ejercicio ordinario en una controversia e implica un desacuerdo con los puntos planteados; es un derecho a la contradicción, lo que nos induce al mundo del derecho y a un ejercicio dialectico, donde las realidades concretas del ser humano se deben someter al imperio de la ley desde una visión normativista y también se presentan argumentos objetivados o a conciencia que impiden la aplicación del derecho. Por tanto, la objeción que es útil para el presente estudio es aquella que busca la inaplicación de una ley o un deber legal obligatorio para las personas en un lugar y tiempo determinado.

Además, objetar implica la exteriorización de una conducta y es ahí donde la objeción de una decisión a conciencia debe tener un sentido histórico, ya que si la misma está determinada por saberes objetivos e interpretaciones subjetivas de un ser, el primer rubro a examen será el ente que contiene ese ser, a fin de verificar si su conducta histórica se desarrolla de forma congruente con su decisión objetivada o a conciencia en relación con la particularidad que se debate, de tal 
forma que la objeción tenga antecedentes referenciados, habituales y comprobables, además que esta conducta se entienda más enfocada a la virtud que a la evasión o rebeldía a un sistema jurídico, de tal forma que la objeción se base en una conducta habitual que ordinariamente se desarrolle. De no existir en la objeción estos elementos de preexistencia de saberes y hábitos harán la exteriorización de la objeción una incongruencia de débil credibilidad.

En concreto, la objeción es un posicionamiento que busca oponerse a la aplicación de un deber y tiene por elementos la preexistencia de saberes y hábitos del objetante, que motivan un hacer o un no hacer, elementos que de comprobar su existencia darán congruencia y credibilidad a la objeción.

\section{3. ¿Qué es la objeción de conciencia?}

Partiendo de las exégesis anteriores de conciencia y objeción, podemos discernir sobre la figura de objeción de conciencia.

Para Capodiferro (2017) "La objeción de conciencia puede definirse como la reacción individual de un sujeto, derivada de la contradicción entre su conciencia y el contenido o fundamento de un deber jurídico que le afecta".

Roca (2008) piensa que: "La objeción de conciencia viene a ser la moral personal que se alza frente a la moral que subyace en la ley".

También Agulles (2006) explica que "La libertad de conciencia implica la garantía, por parte del Estado, de que el juicio personal que emite el individuo, y la adecuación de un determinado comportamiento a él, se va a realizar sin interferencias o impedimentos de cualquier tipo”.

Por tanto, existe coincidencia en vislumbrar a la objeción de conciencia como un medio procesal para alcanzar algo, que lo es la inaplicación de un deber jurídico ante un caso concreto basado en la libertad de pensar.

Sin embargo, esto se puede confundir con la sedición, la revolución, un golpe de Estado o la desobediencia civil colectiva y otras acciones que también buscan impedir que se ejecute un mandato jurídico.

La diferencia entre estas acciones y la objeción de conciencia radica en que la figura en estudio no tiene razones colectivas o implicaciones políticas, sino que se entiende como la exteriorización de una decisión libre individual, objetivada y coherente con los hábitos, saberes y comportamientos 
previos del objetante y siempre se materializa ante un caso concreto individual, donde la decisión consciente u objetivación se opone al supuesto de una hipótesis normativa del derecho vigente.

Por lo tanto, la figura procesal de objeción de conciencia pone a debate a los sistemas jurídicos modernos al surgir como un derecho de contradicción por razones de conciencia, lo que hace necesario el análisis jurídico que se expone en el siguiente capítulo.

\section{La objeción de la conciencia un derecho subjetivo}

En los términos expuestos anteriormente, al reconocer a la objeción de conciencia como un medio procesal de contradicción para inaplicar una norma jurídica, implícitamente estamos otorgándole a la objeción de conciencia el carácter de un derecho, ya que en un sistema jurídico ideal solo se puede inaplicar un derecho cuando el propio orden jurídico así lo permite, por lo que, en el presente capitulo indagaremos el lugar que tiene la objeción de conciencia dentro del sistema jurídico y si existe un derecho subjetivo general que permita su ejercicio, esto con el apoyo del derecho constitucional y la teoría de los derechos humanos.

\section{1. ¿De dónde proviene el derecho a la objeción de conciencia? y ¿cuál es su fundamento legal?}

Al explicar la conciencia se descubrió que esta emana del ser, al igual que la dignidad humana y que con independencia de la condición de ese ser éstas existen, también se abordó la forma que se integra y con ello la imposibilidad de su comprobación científica, pero se refirió a la congruencia y coherencia entre saberes y hábitos personales como parámetros externos para dar valor o credibilidad a una decisión a conciencia u objetivada.

Entonces, si la conciencia está en el ser al igual que la dignidad humana, el parámetro más cercano para dilucidar su lugar en el derecho es el explicar el posicionamiento de la dignidad humana en el sistema jurídico constitucional.

Al respecto Pascal afirma que: "toda dignidad del hombre reside en el pensamiento" (Becchi, 2012), esto implica que el propio pensamiento "posee un valor intrínseco absoluto no ya como animal rationale sino como portador de un imperativo moral incondicionado" (2012); por ello, "no es el mero hecho bilógico el que constituye el fundamento de su dignidad, sino el hecho de la razón de la ley moral y una razón moralmente práctica" (2012). 
En síntesis, el hombre es digno por su condición humana, por la protección de las leyes y por la praxis de la moral de otros hombres. Así pues, en un sistema jurídico garantista de derechos fundamentales se debe potencializar el respeto a la dignidad humana, no sólo por ser un supuesto jurídico aplicable, sino por tratarse de un ser pensante que puede hacer uso de su conciencia.

Esta dignidad humana es fuente de otros derechos como el de la libertad de pensamiento, ya que la conciencia sólo se puede ejercer bajo el esquema de la libertad, de no ser así, no se produciría el proceso de objetivación de la conciencia que se discernió en el capítulo anterior, y se viviría con una conciencia manipulada o acotada, desembocando en una hecatombe social, como la ya vista en el régimen Nazi, donde el poder político se apropió de la conciencia individual y decidió por los personas bajo los parámetros del poder y la ambición y no bajo el parámetro de respeto a la dignidad humana y la libertad del pensamiento.

Por ello, el día que al individuo se le impida el derecho a ejercer su libertad de conciencia y de pensamiento, se estaría bajo una decisión autoritaria que fácilmente se alejaría de los fines sociales y los derechos humanos.

Sin embargo, en términos del artículo 29 segundo párrafo de la Constitución mexicana esto no es posible, ya que ese precepto legal impide la suspensión o restricción de los derechos humanos a las libertades de pensamiento, conciencia y de profesar creencia religiosa alguna, entre otros.

Esto implica la vigencia absoluta del Artículo 24 Constitucional, mismo que afirma: "Toda persona tiene derecho a la libertad de convicciones éticas, de conciencia y de religión, y a tener o adoptar, en su caso, la de su agrado".

En suma, a lo anterior el último párrafo del artículo $1^{\circ}$ de la Constitución prohibe toda discriminación que atente contra la dignidad humana y tenga por objeto anular o menoscabar los derechos y libertades de las personas.

También, la Declaración Americana de los Derechos y Deberes del Hombre en su artículo $1^{\circ}$ establece: "Todo ser humano tiene derecho a la vida, a la libertad y a la seguridad de su persona" y en ese tenor la Corte Interamericana de los Derechos Humanos ha precisado, que: "según el artículo 12 de la Convención Americana, el derecho a la libertad de conciencia y de religión permite que las personas conserven, cambien, profesen y divulguen su religión o sus creencias. Este derecho es uno de los cimientos de la sociedad democrática" ( Corte IDH. Caso, Olmedo Bustos y otros vs. Chile, 2001). 
Continuando con el derecho convencional el artículo 12 de la Convención Americana de los Derechos Humanos, indica:

Libertad de Conciencia y de Religión

1. Toda persona tiene derecho a la libertad de conciencia y de religión. Este derecho implica la libertad de conservar su religión o sus creencias, o de cambiar de religión o de creencias, así como la libertad de profesar y divulgar su religión o sus creencias, individual o colectivamente, tanto en público como en privado.

2. Nadie puede ser objeto de medidas restrictivas que puedan menoscabar la libertad de conservar su religión o sus creencias o de cambiar de religión o de creencias.

3. La libertad de manifestar la propia religión y las propias creencias está sujeta únicamente a las limitaciones prescritas por la ley y que sean necesarias para proteger la seguridad, el orden, la salud o la moral públicos o los derechos o libertades de los demás.

4. Los padres, y en su caso los tutores, tienen derecho a que sus hijos o pupilos reciban la educación religiosa y moral que esté de acuerdo con sus propias convicciones (Steiner y Uribe, 2014, p. 289).

De este precepto se desprende que a nivel convencional se protege la libertad de conciencia y religión, esta protección se materializa principalmente en la libertad religiosa y se asocia en el rubro de educación a la moral. No obstante, la razonabilidad de conciencia en otros órdenes del pensamiento no tiene la misma protección de forma expresa. Sin embargo, al entenderse el derecho como un sistema se correlaciona el caso en estudio con el artículo 6 numeral 3 b) de la antes citada Convención, en materia de Prohibición de la Esclavitud y Servidumbre, mismo que a su letra dice:

3. No constituyen trabajo forzoso u obligatorio, para los efectos de este artículo:

a.

b. El servicio militar y, en los países donde se admite exención por razones de conciencia, el servicio nacional que la ley establezca en lugar de aquél. 
Además, el Comité de Derechos Humanos de la Organización de las Naciones Unidas emitió una observación con el numero CCPR-GC-22 titulada "Libertad de pensamiento, de conciencia y de religión", misma que en su párrafo 3 establece:

"El artículo 18 distingue entre la libertad de pensamiento, de conciencia, de religión o de creencias y la libertad de manifestar la propia religión o las propias creencias. No permite ningún tipo de limitación de la libertad de pensamiento y de conciencia o de la libertad de tener la religión o las creencias de la propia elección, estas libertades están protegidas incondicionalmente."

En síntesis, la libertad de conciencia esta reconocida en la constitución mexicana específicamente en el artículo 24 y en términos del articulo 29 de la propia Carta Magna, esta libertad de conciencia no puede ser suspendida y más aún, según lo dispuesto en el artículo $1^{\circ}$ Constitucional, la libertad de conciencia tampoco puede ser objeto de discriminación alguna, esto en coherencia con lo resuelto por el Comité de Derechos Humanos de la Organización de las Naciones Unidas (ONU) y fundado también en normas convencionales del Sistema Interamericano de Derechos Humanos. Por tanto, la libertad de conciencia y de pensamiento es un derecho humano que tiene por núcleo la praxis de la libertad del pensamiento.

Por último, se expone, una exegesis orientadora para la praxis de la libertad de conciencia basada en el preámbulo de la Declaración Americana de los Derechos y Deberes del Hombre, que a su letra dice:

- Todos los hombres nacen libres e iguales en dignidad y derechos y, dotados como están por naturaleza de razón y conciencia, deben conducirse fraternalmente los unos con los otros.

- El cumplimiento del deber de cada uno es exigencia del derecho de todos. Derechos y deberes se integran correlativamente en toda actividad social y política del hombre. Si los derechos exaltan la libertad individual, los deberes expresan la dignidad de esa libertad.

- Los deberes de orden jurídico presuponen otros, de orden moral, que los apoyan conceptualmente y los fundamentan.

- Es deber del hombre servir al espíritu con todas sus potencias y recursos porque el espíritu es la finalidad suprema de la existencia humana y su máxima categoría. 
- Es deber del hombre ejercer, mantener y estimular por todos los medios a su alcance la cultura, porque la cultura es la máxima expresión social e histórica del espíritu.

- Y puesto que la moral y buenas maneras constituyen la floración más noble de la cultura, es deber de todo hombre acatarlas siempre.

Este texto establece los principios que se pueden optimizar en el caso de una resolución que verse sobre libertad de conciencia bajo los siguientes postulados:

a) Todo hombre está dotado del uso de la razón y de una capacidad reflexiva que le permite objetivar su conciencia;

b) Los hombres deben usar su capacidad de razón y de conciencia de una forma fraternal con sus semejantes;

c) La conciencia y las decisiones derivadas de ella deben estar delimitada en un ejercicio imperativo-atributivo respecto a los derechos de los demás y el bien de la sociedad;

d) Los deberes establecidos en el orden jurídico vigente están basados en otros deberes y conductas preexistentes, de tal forma que toda decisión a conciencia u objetivada para tener congruencia debe estar intrínsecamente vinculada con hábitos y conductas coherentes ordinarias con ella;

e) La espiritualidad del humano y su libertad de pensamiento representan la más alta categorización del ser, por lo que se debe permitir que el hombre sirva al espíritu como forma para alcanzar su realización y practicar su libertad de pensamiento;

f) La materialización colectiva del espíritu y la conciencia se da a través de la cultura y las reflexiones que conforman la teología, la filosofía del derecho y diversas expresiones culturales;

g) En una cultura noble están intrínsecas la moral y las buenas costumbres, por ello el derecho y la libertad del pensamiento deben motivar su desarrollo.

Bajo esta interpretación del preámbulo de la Declaración Americana de los Derechos y Deberes del Hombre se puede partir para la creación de los derechos subjetivos que permitan materializar la libertad de conciencia y libertad del pensamiento, ya que es incongruente que se le reconozca 
como un derecho humano y no exista una acción generalizada que permita al individuo ejercer la objeción de conciencia para no acatar o inaplicar un imperativo jurídico, tal como se analiza a continuación.

\section{2. ¿En el sistema jurídico mexicano como se ejerce el derecho humano a la objeción de conciencia?}

Bajo estos fundamentos el Estado mexicano está obligado a tener recursos judiciales o administrativos efectivos que tengan por objeto tutelar el derecho humano a la libertad de conciencia y de pensamiento, esto en términos del artículo 25, numeral 1, de la Convención Americana sobre Derechos Humanos (Pacto de San José de Costa Rica). Por ello, es necesario explorar en las normas jurídicas mexicanas que recursos existen vigentes para que permitan el respeto a la libertad de conciencia y de pensamiento, encontrado que la Ley General de Salud en su artículo $10^{\circ} \mathrm{Bis}$ refiere:

El Personal médico y de enfermería que forme parte del Sistema Nacional de Salud, podrán ejercer la objeción de conciencia y excusarse de participar en la prestación de servicios que establece esta Ley. Cuando se ponga en riesgo la vida del paciente o se trate de una urgencia médica, no podrá invocarse la objeción de conciencia, en caso contrario se incurrirá en la causal de responsabilidad profesional. El ejercicio de la objeción de conciencia no derivará en ningún tipo de discriminación laboral.

Al respecto de la aprobación de este precepto, ONU Mujeres manifestó que "la libertad de pensamiento, de conciencia y de religión, está reconocido en la Declaración Universal de Derechos Humanos y en el Pacto Internacional de Derecho Civiles y Políticos. Sin embargo, el ejercicio de este derecho en ninguna circunstancia debe representar un obstáculo para el acceso oportuno, aceptable, asequible y de calidad a la atención de la salud" (ONU Mujeres, UNFPA y ONU-DH, 2018). Posicionamiento que deja claro que la objeción de conciencia es un derecho humano, pero que en ningún caso este debe impedir que otras personas disfruten de la tutela de otros derechos humanos, por tanto, la praxis de la objeción de conciencia se debe concebir en un mundo circundante que considera al derecho como un saber objetivo de aplicación obligatoria, que buscará siempre la tutela de los derechos humanos dentro de un Estado moderno (democrático). 
Otro caso concreto de objeción de conciencia que se encontró en el sistema jurídico mexicano lo fue el del servicio militar, rubro en el que se profundiza con la siguiente tesis:

SERVICIO MILITAR NACIONAL. LAS EXCEPCIONES PREVISTAS EN EL ARTÍCULO 38 DEL REGLAMENTO DE LA LEY RESPECTIVA TIENEN UNA FINALIDAD CONSTITUCIONAL, EN TANTO QUE ATIENDEN AL INTERÉS GENERAL Y AL RESPETO DE LOS DERECHOS HUMANOS.

La Ley del Servicio Militar señala que las causas de excepción total o parcial para el servicio de las armas deberán reglamentarse en función de que los excluidos posean impedimentos físicos, morales o sociales, lo cual los torne en elementos no útiles para lograr una movilización eficaz; en este sentido, de su exposición de motivos se advierte que el servicio militar es obligatorio para que aquellos habitantes que resulten útiles estén disponibles en caso de que se requiera realizar una movilización eficaz de cuantos contingentes reclame la patria para enfrentarse a cualquier peligro. De lo anterior deriva que dicha finalidad no se alcanza con determinados grupos de mexicanos que se ubiquen en los supuestos de exclusión, pues no son útiles para lograr la movilización descrita por actualizarse en ellos impedimentos de carácter físico, moral o social. En este orden de ideas, las razones que justifican como excepción a los altos servidores públicos y a los miembros de los cuerpos policiacos, están enfocadas al interés público, pues tanto unos como los otros deben cumplir con las funciones y trabajos propios del cargo con diligencia y probidad, a fin de salvaguardar la legalidad, honradez, lealtad, transparencia, imparcialidad y eficiencia en el desempeño de sus funciones, empleos, cargos o comisiones, lo cual implica que si a la par del cargo como servidores públicos estuvieran obligados a prestar el servicio militar, esto pudiera distraerlos de sus altas funciones, con lo que se estaría faltando a su deber si éstas no las realizan con el máximo cuidado. Mientras que las excepciones relativas a los ministros de culto y a los candidatos a puestos de elección popular, si bien también tienen esa finalidad, lo cierto es que están justificadas en el respeto y garantía de los derechos humanos de aquellos que se colocan en dichas hipótesis, ya que de no establecerse tales excepciones serían irremediablemente violados por el Estado. Ahora bien, en el caso de los ministros de culto, otra razón subyacente es el respeto del derecho humano a la libertad de conciencia y de religión contenido en el artículo 24 de la Constitución Política de los Estados Unidos Mexicanos, el cual se materializa a través de la "objeción de conciencia", que se reconoce conjuntamente en los artículos 12 y 6.3, inciso b), de la Convención 
Americana sobre Derechos Humanos, mientras que en el caso de los candidatos a puestos de elección popular, su excepción se justifica en el hecho de que no pueden ser distraídos de sus campañas para prestar el servicio militar nacional, sin que ello transgreda su derecho político a ser votado en condiciones de igualdad. Consecuentemente, en tanto que las excepciones atienden a impedimentos de orden social, éstas son objetivamente constitucionales (Tesis 1a. CXLVI/2012 [10a.], 2012, p. 502).

Se establecen en este criterio del Poder Judicial Federal mexicano las causas de excepción por objeción de conciencia e impedimentos del orden social, para el cumplimiento del servicio militar nacional, precisando claramente que los ministros de culto tienen un derecho a la libertad de conciencia: fundamento para impedir la obligatoriedad del derecho en la materia que se describe, aunque según este razonamiento jurisdiccional no es el mismo caso de los jóvenes que no quieren participar por cuestiones morales, a ellos se les da el carácter de elementos no útiles y a los candidatos o servidores públicos se les excepciona por la naturaleza de su potestad o fin público. Interpretación que pareciera que sólo los ministros de culto tienen derecho a exceptuar el cumplimiento de esta ley por razón de un derecho de libertad de conciencia.

También, es oportuno reflexionar en torno a que en el sistema jurídico mexicano solo se encuentra contemplado el derecho a la objeción de conciencia en los casos de aborto y de servicio militar, dejando en la incertidumbre cualquier otra hipótesis de objeción de conciencia, con lo que se incumple con la obligación convencional antes precisada, de tener un recurso judicial o administrativo que tutele el derecho humano a la libertad de conciencia.

Empero, sería un error pensar en una ley que describa todas las hipótesis fácticas particulares, precisando cada caso de objeción de conciencia, ya que el solo enlistarlos ya es una limitación a la libertad del pensamiento, por lo que se debe pensar en la creación de un derecho general a la objeción de conciencia, "de carácter ilimitado o privilegiado que deba ser aceptado en todo caso o condición (Capodiferro Cubero, Daniel, 2017)”.

Aunque es prudente mencionar que al ser un derecho subjetivo entendido como una facultad que busca defender el derecho a la libertad de conciencia y pensamiento, su destino bajo esta propuesta de acción generalizada, será el de colisionar con otros derechos humanos y en caso de solicitar una inaplicación de una ley, deberá resolverse bajo los procedimientos ya prestablecidos por la Suprema Corte de Justicia de la Nación, que los son el test de proporcionalidad y la ley de 
la ponderación, mismas que tiene los siguientes parámetros (Tesis 1a. 2013156/2016 CCLXIII/[10] $]$, p. 915):

A) Que la objeción de conciencia persiga un fin constitucionalmente válido;

B) Que la medida resulte idónea para satisfacer en alguna medida su propósito constitucional;

C) Que no existan medidas alternativas igualmente idóneas para lograr dicho fin o menos lesivas para el derecho fundamental; y

D) Que el grado de realización del fin perseguido sea mayor al grado de afectación provocado al derecho fundamental por la inaplicación solicitada.

Esto significa que para resolver la inaplicación de una ley o la justificación del incumplimiento de un deber jurídico derivado del ejercicio del derecho subjetivo de objeción conciencia, basada en el derecho humano a la libertad de conciencia y de pensamiento, tendrá que ser ponderado contra otros derechos humanos, con los que aparentemente se esté oponiendo, bajo la reglas de fin legítimo, idoneidad, necesidad y proporcionalidad aclarando que el derecho a la libertad de conciencia o del pensamiento no tiene ningún estatus de privilegio prestablecido contra otros derechos tutelados.

De tal forma que el derecho humano a la libertad de conciencia y pensamiento tendrá que aprender a convivir con el pluralismo de otros derechos humanos teniendo como limite siempre la dignidad humana. En ese sentido la objeción de conciencia enriquece el pluralismo jurídico, lo que se explica de la siguiente forma:

El pluralismo, entendido como respeto a la diversidad de sistemas de valores o cosmovisiones presentes en una sociedad que no es homogénea, como lo era hace siglos, parece tener un límite en la dignidad de la persona. Toda diversidad se puede respetar, acogiendo un verdadero pluralismo, mientras no resulte afectado el debido respeto a la dignidad de la persona. (Roca, 2008, p. 41) 


\section{Bases mínimas para una legislación en materia de objeción de conciencia}

En la presente sección se exponen unas bases mínimas para el ejercicio de un derecho subjetivo generalizado denominado: "Acción de objeción de conciencia para incumplir un deber legal". El debate para alcanzar un consenso sobre las bases mínimas de esta acción procesal debe partir de realidades concretas, en el contexto de la sociedad de su tiempo y no en una diferenciación del derecho y la moral, o en una unificación de estas. Si se comete el error de creer que la institucionalización procesal de la objeción de conciencia será un triunfo o derrota de la aplicación de la ley o de la moral, entonces se obstaculizará su promulgación y con ello se continuará con la incertidumbre jurídica para el ejercicio de este derecho humano. $\mathrm{O}$ en su caso prevalecerá sobre la conciencia el perspectivismo del poder político en turno. Esto sin olvidar el valor para el orden social del sistema jurídico y su obligatoriedad, ya que sería una utopía pensar que el hombre puede prescindir de la aplicación del derecho y guiarse exclusivamente de ejercicios reflexivos de conciencia.

Por ello, la propuesta es crear las bases mínimas para la procedencia de un derecho subjetivo o una acción procesal para que un órgano jurisdiccional valore cada caso en lo individual, a fin de que no existan excesos que pongan en riesgo el régimen jurídico, pero tampoco deficiencias que lleven al incumplimiento de la tutela en materia de libertad de conciencia y pensamiento. Esto sin olvidar lo complicado que será para un juez el comprobar la existencia de un proceso racional basado en un ejercicio de conciencia, por ello, se propone que se generen bases mínimas tomando en consideración criterios, conductas y hábitos ya preexistentes por parte de los objetores.

Por tanto, el derecho a la objeción para inaplicar una ley o norma jurídica o justificar el incumplimiento de un deber jurídico debe tener las siguientes bases mínimas:

1. Que busque tutelar el derecho humano la libertad de conciencia y pensamiento sin impedir su interdependencia con otros derechos humanos;

2. Que el objetante en su argumentación contemple tanto los elementos objetivos de la sociedad en la que vive (derecho, moral, cultura, religión) y las interpretaciones que él le otorga a esos elementos;

3. Que el objetante exprese en una relatoría de hechos y adoctrinamiento que ha realizado previamente en congruencia con la decisión que hoy defiende; 
4. Que el propio objetante exponga si el incumplimiento de su deber jurídico causa daño o perjuicio a alguien y como propone resolverlo;

5. Que el objetante exprese ser conocedor y estar consciente de los efectos y sanciones jurídicas que le acarreará el incumplimiento de ese deber jurídico;

6. Que el objetante pueda en propia voz explicar las razones que le impiden cumplir con la ley;

7. Que el objetante exprese si a pesar de no recibir una sentencia que le permita la inaplicación o justificación de su deber jurídico, se muestra conforme con la decisión adoptada por el, en el sentido de incumplir el marco jurídico aplicable.

Con estos elementos el juzgador podrá evaluar si existe un proceso de objetivación o decisión a conciencia, si este es fruto real de un discernimiento profundo del ser, si este discernimiento tomo en cuenta las obligaciones contenidas en la ley y las valoro contra los motivos de su objeción, si existe la posibilidad de causar daños a terceros o si está en riesgo la aplicación de algún derecho humano a favor de un tercero, si la objetivación de la conciencia es por mutuo propio o manipulada, si la decisión de no cumplir la ley es tan firme que genera un estatus de bienestar al objetante y si realmente lo que se busca de fondo en la objeción es el ejercicio del derecho humano a la libertad de conciencia y del pensamiento o se tiene otros fines que pueden ser atendidos mediante otras acciones procesales existentes en el sistema jurídico vigente.

En consecuencia, estas bases buscan orientar tanto al objetante como al juzgador y al legislador para escudriñar sobre la esencia, objetivo, consecuencias y tutela de una acción de objeción de conciencia.

\section{Conclusiones}

Primera. - La conciencia se integra de elementos objetivos ideales que se extraen del mundo circundante (derecho, ciencia) y de elementos subjetivos que son los conocimientos empíricos, que el individuo tiene, los cuales se integran o complementan en el acto de objetivación y se externan en forma de razones a las cuales en derecho se les llama argumentos.

Segunda. - El derecho humano a la libertad de conciencia se debe extender expresamente a los ámbitos filosófico, político, histórico, sanitario, militar y cualquier otro, estableciendo 
principios que sean susceptibles de ser aplicados ante fenómenos concretos y en un contexto social determinado.

Tercera. - Se debe crear en la ley, un derecho subjetivo generalizado de objeción de conciencia para que un individuo pueda ejercitarlo ante una problematización concreta, en la que se enfrente la conciencia y el derecho vigente, también esto permitirá la existencia de un recurso judicial o administrativo efectivo para tutelar el derecho humano a la libertad de conciencia y pensamiento.

Cuarta. - El riesgo de crear un catálogo de casos de procedencia de objeción de conciencia, es delimitar la reflexión humana y el pensamiento a ellos, por eso se propone una acción procesal abierta que permita el análisis concreto de cada caso en un contexto moral, espiritual, cultural y jurídico.

Quinta. - La conciencia y la dignidad humana salen del ser y tiene su fundamento con la sola existencia del ser humano.

Sexta. - La libertad de conciencia y de pensamiento son un derecho humano reconocido por la Constitución Política de los Estados Unidos Mexicanos y los tratados internacionales en materia de derechos humanos en los que México es parte.

Séptima. - Jurídicamente es imposible comprobar que una decisión de incumplir un deber legal es realmente fruto de un acto de discernimiento a conciencia, empero si pueden existir parámetros basados en hábitos y decisiones previas que permitan vislumbrar congruencia del objetante.

Octava. - Las bases mínimas para ejercitar una acción de objeción de conciencia para incumplir un deber legal, buscan examinar si el derecho tutelado en la objeción es la libertad de conciencia o del pensamiento, si este es fruto de un discernimiento a conciencia y si existe la posibilidad de poner en riesgo los derechos humanos de terceras personas, así como evitar que la objeción de conciencia se convierta en una vía para atacar al Estado de derecho.

Novena. - La objeción de conciencia debe ser tutelada mediante un recurso judicial o administrativo generalizado y efectivo, además debe ser ponderada contra otros derechos humanos de la misma persona o terceros al momento de emitir su resolución. 


\section{Referencias}

Agulles Simó, Pau. (2006). La objeción de conciencia farmacéutica en España, Pontificia

Università della Santa Croce, Roma. pág. 22, 25. Recuperado de

http://www.eticaepolitica.net/bioetica/pa_01_objec_conc_farmaceutica_espana(es).pdf

Becchi, P. (2012). El principio de la dignidad humana. México, Fontamara.

Capodiferro Cubero, Daniel. (2017). El tratamiento de la objeción de conciencia en el Consejo de

Europa, 'Ilu. Revista de Ciencias de las Religiones, Ed. Complutense, España, pág. 72- 95.

CORTE IDH (2001). Olmedo Bustos y otros vs. Chile. Caso "La Última Tentación de Cristo".

Fondo, Reparaciones y Costas. Sentencia de 5 de febrero de 2001. Serie C No. 73, Párrafo 79.

CORTE IDH. (17 de septiembre de 2003). Opinión Consultiva OC-18/03.

Tesis CXLVI/2012 (10a.). Semanario Judicial de la Federación y su Gaceta Primera, Décima Época, agosto de 2012.

DICCIONARIO DEL ESPAÑOL DE MÉXICO (2019), Disponible en http://dem.colmex.mx https://www.sitios.scjn.gob.mx/codhap/sites/default/files/acc_ref/Convencion_Americana_sobre_

Derechos_final.pdf

Gambra, R. (1996). Historia sencilla de la Filosofía. Madrid: Rialp.

Heidegger, M. (2007). Seminarios de Zollikon. México: Red de Utopía A.C.

Kant, I. (2012). Crítica de la razón pura. México: Porrúa.

Martínez-Torrón, J. (2005). Las objeciones de conciencia de los católicos. Revista General de Derecho Canónico y Derecho Eclesiástico del Estado. 9, 87-109.

Ollero, A. (2001). Democracia y convicciones en una sociedad plural. Pamplona: Navarra Gráfica.

ONU Mujeres, UNFPA y ONU-DH (2018). La objeción de conciencia no debe significar un obstáculo o retroceso para el ejercicio efectivo de los derechos humanos: recuperado por: http://mexico.unwomen.org/es/noticias-y-eventos/articulos/2018/04/interrupcionembarazo

Roca, María. (2008). Opciones de conciencia. Propuestas para una ley. Valencia: Tirant lo Blanch, pp. 41.

Sánchez, R. (2016). Posibilidades prácticas y posibilidades modales como base de actos reales en el curso Introducción a la filosofía de Edmundo Husserl. Pensamiento: Revista de investigación e información filosófica, 72(270), 103-117. 
Sánchez, R. (2016). Motivación de los procesos pre-significativos y asociativos en la conciencia de imagen: hostilidad y vida natural. Eikasia, Revista de filosofía. Recuperado de https://www.researchgate.net/publication/311571768_Motivacion_de_los_procesos_presi gnificativos_y_asociativos_en_la_conciencia_de_imagen_hostilidad_y_vida_natural

Starck, c. (1990). Zur Notwendifkeit einer Werbegundung des Rechts. ARSP, 37.

Steiner, C. y Uribe, P. (2014). Convención Americana sobre Derechos Humanos. México: Suprema Corte de Justicia de la Nación. Recuperado en https://www.sitios.scjn.gob.mx/codhap/sites/default/files/acc_ref/Convencion_Americana _sobre_Derechos_final.pdf 